T. Hubert $\cdot$ T. Jany $\cdot$ S. Marcelli-Tourvieille $\cdot$ B. Nunes $\cdot$

V. Gmyr · J. Kerr-Conte · M.-C. Vantyghem $\cdot$ F. Pattou

\title{
Acute insulin response of donors is correlated with pancreatic islet isolation outcome in the pig
}

Received: 21 February 2005 / Accepted: 5 May 2005 / Published online: 26 August 2005

(C) Springer-Verlag 2005

\begin{abstract}
Aims/hypothesis: Unpredictability of islet isolation outcome remains a frustrating and costly issue in the clinical implementation of islet transplantation. The aim of this experimental study was to test the hypothesis that the donor's insulin secretory reserve, an in vivo surrogate of functional pancreatic mass, is correlated with the outcome of islet isolation. Methods: Insulin secretory reserve was evaluated in 28 healthy adult minipigs prior to pancreatectomy and islet isolation. Blood glucose and insulinaemia were measured before and 1, 3, 5, 10, 15, 30, 60 and $90 \mathrm{~min}$ after glucose infusion. Following total pancreatectomy, islet isolation was performed according to Ricordi's semi-automated method, and the total number of islets obtained was determined. Fasting blood glucose, insulinaemia, acute insulin response (AIR), maximal insulinaemia and the glucose decay constant $\left(K_{\mathrm{G}}\right)$ were calculated, and possible associations with the outcome of islet isolation were assessed. Results: AIR and maximal insulinaemia after glucose injection were correlated with the outcome of islet isolation $(p<0.01)$. Mean values for AIR and maximal insulinaemia were significantly different between animals in which islet isolation was successful $(n=11)$ vs those in which it was unsuccessful $(n=17)$ $(77.6 \pm 13.7 \mu \mathrm{U} / \mathrm{ml}$ vs $42.3 \pm 7.8 \mu \mathrm{U} / \mathrm{ml}, p<0.05 ; 144.7 \pm$ $21.6 \mu \mathrm{U} / \mathrm{ml}$ vs $71.9 \pm 10.4 \mu \mathrm{U} / \mathrm{ml}, p<0.05$, respectively). Conclusions/interpretation: This study suggests that the donor's pancreatic endocrine mass, as estimated by AIR, is a major determinant of the outcome of islet isolation in large mammals. Our results may explain the frustrating variability of human islet isolation outcome and could lead to a new approach for optimising the selection of brain-dead and/or living pancreas donors.
\end{abstract}

T. Hubert $\cdot$ T. Jany $\cdot$ S. Marcelli-Tourvieille $\cdot$ B. Nunes

V. Gmyr · J. Kerr-Conte $\cdot$ M.-C. Vantyghem $\cdot$ F. Pattou $(\triangle)$

Lille II University,

INSERM ERIT-M 0106 Diabetes Cell Therapy,

University Hospital,

1 place de Verdun,

59045 Lille Cedex, France

e-mail: fpattou@univ-lille2.fr

Tel.: +33-3-20626963

Fax: +33-3-20626983
Keywords Acute insulin response - Diabetes - Insulin · Islet $\cdot$ Isolation $\cdot$ Pancreas $\cdot$ Pig $\cdot$ Transplantation

Abbreviations AIR: Acute insulin response - IEQ: Islet equivalent count

\section{Introduction}

Pancreatic islet allotransplantation for the treatment of type 1 diabetes is becoming more widely accepted [1]. Endogenous secretion of insulin to near physiological levels can be restored by intraportal infusion of pancreatic islets derived from brain-dead or, as recently described, living donors [2]. Unfortunately, the variability of human islet isolation outcome remains an exasperating and expensive issue in clinical islet transplantation [1]. Despite significant technical improvements, results remain highly dependent on donor characteristics and on the conditions of pancreas procurement and storage [3-6]. Potential donors are, therefore, habitually selected according to non-specific criteria derived from retrospective analysis of large series of human islet isolation [7]. However, in most centres, barely more than half of the processed pancreata reach the threshold value for islet equivalents required for clinical transplantation $[7,8]$.

We propose that the major determinant of islet isolation outcome is the effective islet mass present in the donor's pancreas. The aim of the present study was to test this hypothesis in the minipig by measuring an in vivo surrogate of islet mass, insulin secretion after glucose injection, and the number of islets obtained after a standard isolation procedure following pancreatectomy.

\section{Materials and methods}

Study design Endocrine cell mass was assessed in 28 nonsyngenic adult minipigs (39.3 $\pm 2.1 \mathrm{~kg} ;>2$ years old; Denis' breeding, Templeuve, France), $48 \mathrm{~h}$ prior to pancreatectomy and islet isolation. The animals were treated in ac- 
cordance with French regulations and our institutional ethical committee, and were housed at our institution in the University Hospital Department of Experimental Research. All surgical procedures were performed $30 \mathrm{~min}$ after the administration of a $10-\mathrm{mg}$ subcutaneous injection of nalbuphine (Merck, Paris, France), an intramuscular injection of $0.3 \mathrm{mg} / \mathrm{kg}$ midazolam (Hypnovel; Roche, Neuilly-sur-Seine, France) and $5 \mathrm{mg} / \mathrm{kg}$ ketamine (Ketalar; Pfizer, Paris, France). Tracheal intubation was performed after curarisation with $0.1 \mathrm{mg} / \mathrm{kg}$ pancuronium (Pavulon; Organon, Fresnes, France) and an antibioprophylactic injection of $1 \mathrm{~g}$ amoxicillin and $200 \mathrm{mg}$ clavulanic acid (Augmentin; SmithKline Beecham, Nanterre, France), under anaesthesia with $0.2 \mathrm{ml} \mathrm{kg}^{-1} \mathrm{~h}^{-1}$ of intravenous propofol (Diprivan; AstraZeneca, Rueil-Malmaison, France). A single-lumen radiopaque silicone catheter (Hickman; Bard, Trappes, France) was initially placed in a jugular vein and exteriorised on the neck of the animal to allow repeated blood samplings.

Endocrine cell mass assessment Blood samples were drawn through the central venous catheter before and 1, 3, $5,10,15,30,60$ and 90 min after intravenous injection of a $0.5 \mathrm{~g} / \mathrm{kg}$ bolus of glucose $(50 \%$ solution; Aguettant Laboratories, Lyon, France). Insulinaemia was determined by RIA (Bi-insuline RIA; Bio-Rad, Elexience, Verrièresle-Buisson, France). Fasting and maximal insulinaemia were also measured. The acute insulin response (AIR) was calculated as the difference between basal insulinaemia and the mean value of insulinaemia measured during the first 5, 10 or $15 \mathrm{~min}$ after glucose injection. The glucose decay constant $\left(K_{\mathrm{G}}\right)$ was calculated according to the following formula: $K_{\mathrm{G}}=[\ln ($ glycaemia at $30 \mathrm{~min})-\ln ($ glycaemia at $5 \mathrm{~min})] /[30-5]$.

Pancreatectomy Total pancreatectomy was performed under general anaesthesia, $24 \mathrm{~h}$ after placing two fentanyl patches with release rates of 25 and $50 \mu \mathrm{g} / \mathrm{h}$, respectively (Durogesic; Janssen-Cilag, Issy-les-Moulineaux, France), as previously described, with cautious dissection to maintain normal vascularisation and to minimise warm ischaemia until excision of the pancreas [9]. The explanted pancreas was immediately cooled in a Ringer-lactate solution at $4^{\circ} \mathrm{C}$.

Islet isolation Within 30 min of cold ischaemia, the pancreas was distended by infusion of porcine collagenase (Liberase, lot number 930026 20; Roche, Meylan, France; enzyme activity: 54,248 U/vial of caseinase (neutral protease), 1821 Wunsch U/vial, $16.52 \mathrm{EU} / \mathrm{mg}$ endotoxin) using two 18-G catheters (Optiva; Ethicon, Pomezia, Italy) inserted in the isthmic portion of the pancreatic duct. Islets were isolated using state-of-the-art methods, including Ricordi's semi-automated method and isopycnic purification using a Euroficoll discontinuous gradient in a cell separator (Cobe 2991 cell processor; Gambro Laboratories, Colombes, France), as previously described [9]. Following dithizone staining (diphenylthiocarbazone; Sigma, Saint-Quentin Fallavier, France), islet mass was assessed by the same investigator (V. Gmyr) throughout the study and expressed in terms of the islet equivalent count (IEQ), the number of islets normalised to a diameter of $150 \mu \mathrm{m}$. Isolation was considered successful when the IEQ exceeded 40,000 , i.e. the minimal islet mass previously shown to avoid diabetes when transplanted after pancreatectomy in the minipig $(1,000 \mathrm{IEQ} / \mathrm{kg})$.

Statistical analysis All data are expressed as means \pm SEM. Pearson's correlation coefficients were calculated to quantify the relationships between donors' characteristics and isolation outcome. When appropriate, the mean values of continuous variables were compared using the MannWhitney $U$ test. Analyses were performed using Statview (SAS, Cary, NC, USA), and p-values less than 0.05 were considered statistically significant. To assess the predictive value of the characteristics, we determined a cut-off value for each of them using a receiver operating characteristic (ROC) curve to calculate positive predictive values for successful isolation.

\section{Results}

On average, the pancreata weighed $47 \pm 3 \mathrm{~g}$. The mean islet volume obtained after isolation was $40,097 \pm 5890$ IEQ There was considerable interindividual variability, both in terms of islet volume (range 7638-133,278 IEQ) and purity (range $20 \%-90 \%$ ). Following a digestion time of $23.5 \pm$ $1.1 \mathrm{~min}, 3.6 \pm 0.9 \mathrm{~g}$ of pancreas was recovered. In 11 cases $(39.3 \%)$, more than 40,000 IEQ were obtained and the isolation procedure was considered successful (see Materials and methods).

In these healthy minipigs, fasting blood glucose was normal $(4.5 \pm 0.4 \mathrm{mmol} / \mathrm{l})$ and was not correlated with the IEQ obtained after isolation $(r=0.05, p=0.78)$. An immediate four- to five-fold increase in insulin levels was observed following glucose injection, the maximum level being reached between 5 and $15 \mathrm{~min}$; insulinaemia subsequently decreased slowly, returning to the basal value at $60-90 \mathrm{~min}$. Fasting insulinaemia $(21.9 \pm 2.7 \mu \mathrm{U} / \mathrm{ml})$ was correlated with the islet isolation outcome expressed in IEQ $(r=0.48, p<0.01)$, and with AIR at $5 \min (58.7 \pm$ $7.9 \mu \mathrm{U} / \mathrm{ml} ; r=0.47, p<0.01)$ and maximal insulinaemia $(103.9 \pm 12.4 \mu \mathrm{U} / \mathrm{ml} ; r=0.56, p<0.01)$ after glucose injection. AIR values calculated at 10 or 15 min were strictly correlated to AIR at $5 \min (r=0.99, p<0.0001) . K_{\mathrm{G}}$ was not correlated with the yield of islets isolated $(r=0.30, p=0.12)$.

Figure 1 shows the results of metabolic evaluation following intravenous glucose injection in animals with successful $(n=11)$ or unsuccessful $(n=17)$ isolation procedures. Comparison of the mean values of these parameters between the two sets of animals (Table 1) revealed that only AIR and maximal insulinaemia were significantly different. Using a threshold value of $65 \mu \mathrm{U} / \mathrm{ml}$, AIR had a sensitivity of $55 \%$ and a specificity of $88 \%$ for predicting successful isolation; applying a cut-off value of $90 \mu \mathrm{U} / \mathrm{ml}$, maximal insulinaemia had a sensitivity of $73 \%$ and a 
Fig. 1 Glycaemia (a) and insulinaemia (b) after an intravenous bolus injection of glucose $(0.5 \mathrm{~g} / \mathrm{kg})$ in minipigs in which the islet isolation procedure was successful (open circles) and in minipigs in which islet isolation was unsuccessful (filled circles). $* p<0.01$ vs pigs in which the procedure was unsuccessful a

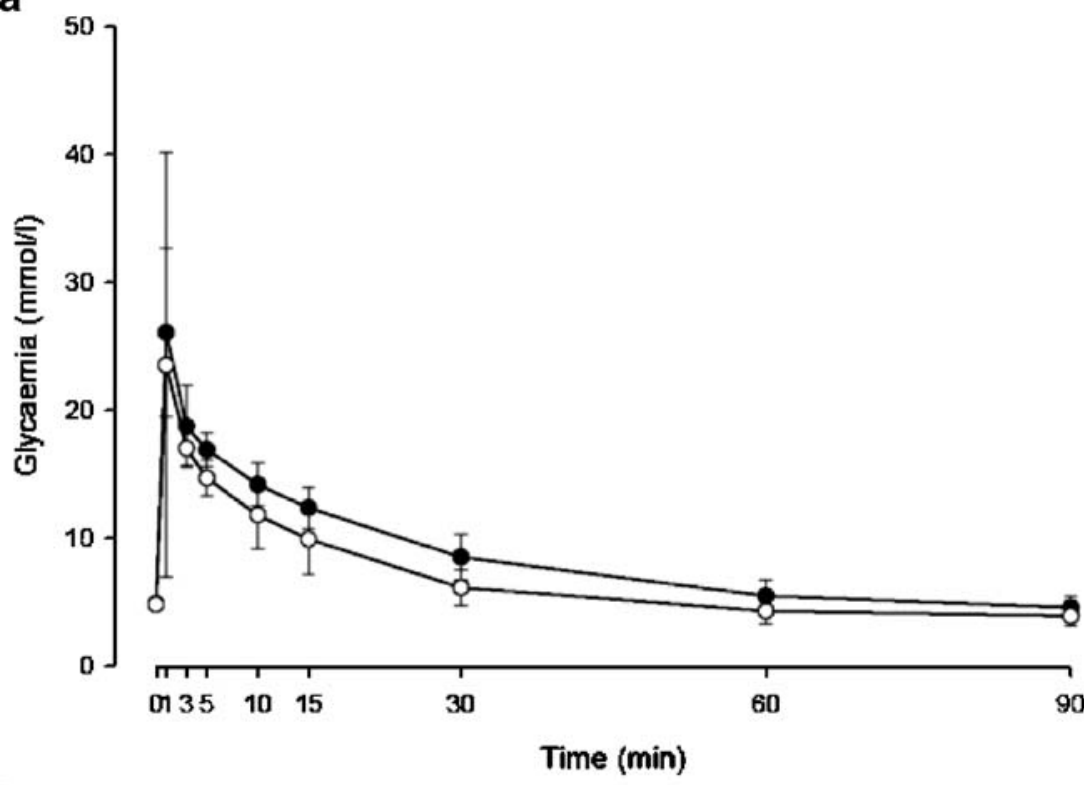

b

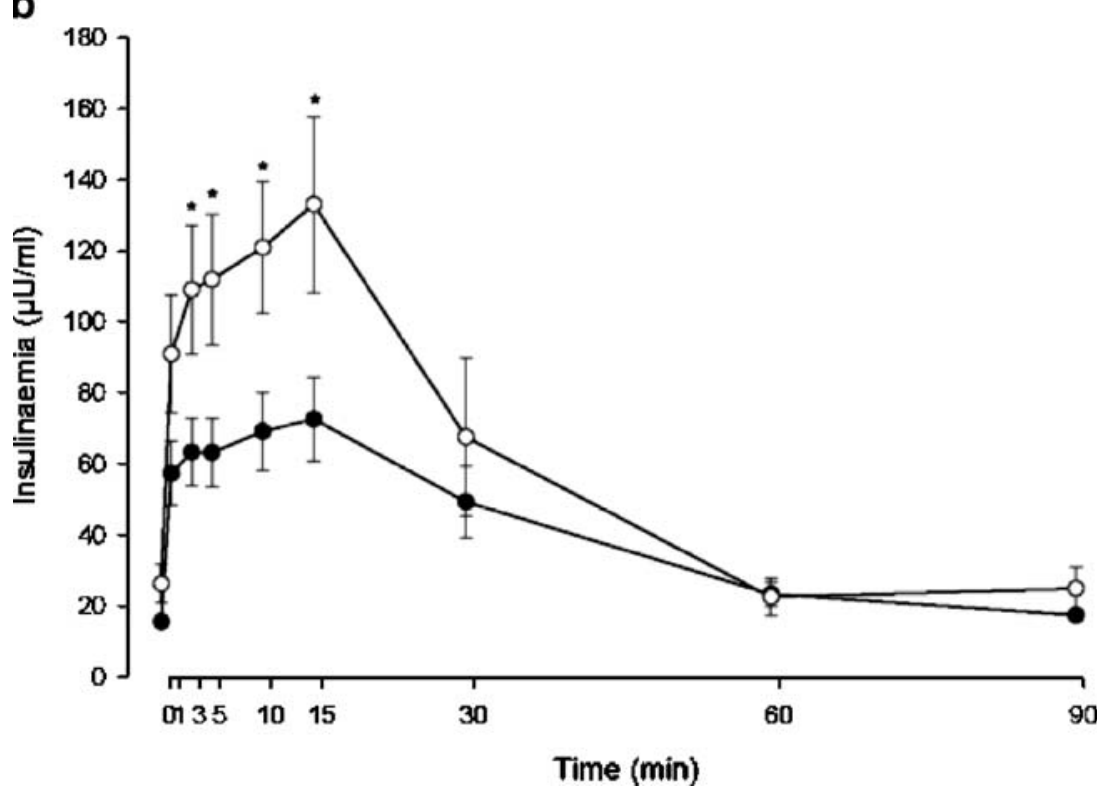

Table 1 Metabolic evaluation in minipigs with successful or unsuccessful islet isolation
Data are shown as means \pm SEM ${ }^{\text {a }}$ Statistically significant by Mann-Whitney $U$-test

\begin{tabular}{lccc}
\hline Parameters measures & Successful isolation & Unsuccessful isolation & $P$-value \\
\hline$n$ & 11 & 17 & \\
Islet mass $(\mathrm{IEQ})$ & $71,867 \pm 7912$ & $19,539 \pm 1972$ & $<0.01^{\mathrm{a}}$ \\
Fasting glycaemia $(\mathrm{mmol} / \mathrm{l})$ & $4.5 \pm 0.4$ & $4.6 \pm 0.4$ & 0.89 \\
Basal insulinaemia $(\mu \mathrm{U} / \mathrm{ml})$ & $26.3 \pm 5.4$ & $18.9 \pm 3.0$ & 0.20 \\
AIR $(\mu \mathrm{U} / \mathrm{ml})$ & & & \\
$5 \mathrm{~min}$ & $77.6 \pm 13.7$ & $42.3 \pm 7.8$ & $0.02^{\mathrm{a}}$ \\
$10 \mathrm{~min}$ & $81.9 \pm 14.0$ & $44.2 \pm 8.2$ & $0.02^{\mathrm{a}}$ \\
$15 \mathrm{~min}$ & $86.9 \pm 15.5$ & $46.0 \pm 8.5$ & $0.02^{\mathrm{a}}$ \\
Maximal insulinaemia $(\mu \mathrm{U} / \mathrm{ml})$ & $144.7 \pm 21.6$ & $71.9 \pm 10.4$ & $0.02^{\mathrm{a}}$ \\
Glucose decay constant $\left(K_{\mathrm{G}}\right)$ & $4.1 \pm 0.4$ & $3.1 \pm 0.4$ & 0.12 \\
\hline
\end{tabular}


specificity of $82 \%$. These two tests had a positive predictive value of $75 \%$ and $73 \%$, respectively.

\section{Discussion}

The poor predictability of human islet isolation outcome remains a frustrating and costly issue in islet transplantation. Most centres currently select potential pancreata after analysing several donor clinical characteristics, such as age, BMI and medical history (e.g. cause of death, length of intensive care). The predictive value of these non-specific criteria, derived from retrospective cohort analyses [3-6], remains limited, with the mean success rate of clinical islet isolation hardly surpassing $50 \%$ even in the most experienced centres $[7,8]$.

In this study, we investigated the relationship between islet isolation outcome and the insulin secretory reserve, a surrogate measure of the donor's islet mass. To simulate the highly heterogeneous clinical characteristics of human donors, we used a non-syngenic herd of adult minipigs. The pig is a notoriously stringent large animal model for islet isolation $[9,10]$ and, like humans, displays large interindividual variability in terms of isolation outcomes. The crude number of islets isolated in this study may appear lower than expected from the results previously reported in Large White adult farm pigs [11]; however, when expressed in islet equivalent count per kilogram, the isolation yields obtained in our adult minipigs were within the same range. As previously reported [9], the quality of islet preparations was further confirmed by the prevention of hyperglycaemia $(7.2 \pm 1.1 \mathrm{mmol} / \mathrm{l})$ one month after islet intraportal autograft in 10 of the $11(91 \%)$ pancreatectomised pigs that received at least $1000 \mathrm{IEQ} / \mathrm{kg}$ (results not shown).

As expected, isolation outcome was highly variable in these animals, with less than half of the isolations classed as successful. Given that all animals were healthy adult pigs and that the procedures used for procurement and processing of the pancreas were normalised, only variations in effective islet mass can explain the observed interindividual variability in islet isolation outcome.

Fasting blood glucose levels and $K_{\mathrm{G}}$, two metabolic parameters that are highly affected by insulin resistance, were not correlated with islet isolation outcome. Conversely, the parameters reflecting basal (fasting insulinaemia) or stimulated (maximal insulinaemia and AIR) insulin secretion were significantly correlated with the outcome of islet isolation. Interestingly, the two measures of stimulated insulin secretion, both of which have previously been shown to be highly correlated with pancreatic islet mass in the minipig [12] and in islet graft recipients [13], were highly predictive of the islet isolation yield in our model. These results confirm, for the first time in a large mammal, that the donor's endocrine mass is a major determinant of islet isolation outcome. Since AIR in humans is positively correlated with BMI [14], our finding could also explain the more favourable outcome regularly observed with pancreata from obese non-diabetic donors $[6,15]$. If prospectively used to select suitable donors from our herd of 28 animals, assessment of maximal insulinaemia would have increased the success rate of islet isolation from $39 \%$ to $73 \%$; we would have missed only three of 11 successful isolations $(27 \%)$ but avoided 14 of 17 unsuccessful procedures $(82 \%)$.

The in vivo assessment of endocrine pancreatic mass could prove of particular value when distal pancreatectomy for islet isolation and transplantation from a healthy living donor are envisaged [2]. Requiring no more than $15 \mathrm{~min}$ and five blood samples, the AIR test could also be implemented during multi-organ procurement and the insulin content obtained within 20 min with automats available in most islet isolation centres (Stat-System; Future Diagnostics, the Netherlands). It should be noted that this study has obvious limitations, since it was performed in healthy animals, neglecting the potential influence of brain death on glucose metabolism and insulin secretion. We are now performing a clinical study to confirm these results in brain-dead human donors before advocating the use of AIR as a donor selection tool. In this context, arginine infusion, which does not increase glycaemia, may represent a more adequate alternative agent for insulin stimulation [12].

In conclusion, this study suggests that the donor's pancreatic endocrine mass, as estimated by AIR, is a major determinant of the outcome of islet isolation in non-syngenic large mammals. These results may explain the heterogeneity observed with respect to human islet isolation outcome, and could lead to the development of a new approach for optimising donor selection and improving the outcome of clinical islet isolation and transplantation.

Acknowledgements T. Hubert and T. Jany contributed equally to this study. T. Hubert was a recipient of a PhD stipend from INSERM ("Poste d'Accueil INSERM Vétérinaire"). The authors are particularly grateful to M. D'Herbomez (Department of Nuclear Medicine, University Hospital of Lille, France), for performing the insulin RIAs; to S. Belaïch, S. Delautel and I. Aluka for their technical expertise during islet isolations; to A. Dumont for his surgical help and to M. Pottier and A. Dive (University Hospital Department of Experimental Research, University Hospital, Lille II University, Lille, France) for animal care.

\section{References}

1. Robertson RP (2004) Islet transplantation as a treatment for diabetes - a work in progress. N Engl J Med 350:694-705

2. Matsumoto S, Okitsu T, Iwanaga Y et al (2005) Insulin independence after living-donor distal pancreatectomy and islet allotransplantation. Lancet 365:1642-1644

3. Benhamou PY, Watt PC, Mullen Y et al (1994) Human islet isolation in 104 consecutive cases. Factors affecting isolation success. Transplantation 57:1804-1810

4. Lakey JR, Warnock GL, Rajotte RV et al (1996) Variables in organ donors that affect the recovery of human islets of Langerhans. Transplantation 61:1047-1053

5. Toso C, Oberholzer J, Ris F et al (2002) Factors affecting human islet of Langerhans isolation yields. Transplant Proc 34:826-827

6. Nano R, Clissi B, Melzi R et al (2005) Islet isolation for allotransplantation: variables associated with successful islet yield and graft function. Diabetologia 48:906-912 
7. Hering BJ, Kandaswamy R, Ansite JD et al (2005) Singledonor, marginal-dose islet transplantation in patients with type 1 diabetes. JAMA 293:830-835

8. Tsujimura T, Kuroda Y, Avila JG et al (2004) Influence of pancreas preservation on human islet isolation outcomes: impact of the two-layer method. Transplantation 78:96-100

9. Pattou F, Kerr-Conte J, Amrouni H et al (1995) Ultimate assessment of pig islet isolation by autotransplantation after pancreatectomy. Transplant Proc 27:3403-3404

10. Gray DW (1999) Porcine islet isolation: a real advance? Transplantation 68:325-326

11. Brandhorst H, Brandhorst D, Hering BJ, Bretzel RG (1999) Significant progress in porcine islet mass isolation utilizing liberase HI for enzymatic low-temperature pancreas digestion. Transplantation 68:355-361
12. Larsen MO, Rolin B, Wilken M, Carr RD, Gotfredsen CF (2003) Measurements of insulin secretory capacity and glucose tolerance to predict pancreatic beta-cell mass in vivo in the nicotinamide/streptozotocin Göttingen minipig, a model of moderate insulin deficiency and diabetes. Diabetes 52:118-123

13. Teuscher AU, Kendall DM, Smets YF, Leone JP, Sutherland DE, Robertson RP (1998) Successful islet autotransplantation in humans: functional insulin secretory reserve as an estimate of surviving islet cell mass. Diabetes 47:324-330

14. Ferrannini E, Mari A (2004) Beta cell function and its relation to insulin action in humans: a critical appraisal. Diabetologia 47:943-956

15. Matsumoto I, Sawada T, Nakano M et al (2004) Improvement in islet yield from obese donors for human islet transplants. Transplantation 78:880-885 